\title{
PROSEDUR PEMERIKSAAN CT CARDIAC DENGAN KASUS CORONARY ARTERY BY PASS GRAFTING (CABG) DI INSTALASI RADIOLOGI MRCCC SILOAM HOSPITAL SEMANGGI
}

\section{PROCEDURE OF CARDIAC CT EXAMINATION WITH CORONARY ARTERY BY PASS GRAFTING (CABG) AT RADIOLOGY INSTALLATION OF MRCCC SILOAM HOSPITAL SEMANGGI}

\author{
Atika Dian Utami ${ }^{1)}$, Yeti Kartikasari ${ }^{2}$, Sigit Wijokongko ${ }^{3)}$ \\ ${ }^{1,2)}$ Health Polytechnies of Semarang-Indonesia \\ ${ }^{3)}$ Tugurejo Semarang Hospital \\ e-mail : atika24dianutami@gmail.com
}

\begin{abstract}
Background : Coronary Artery By Pass Grafting (CABG) is one of the intervention treatments of Coronary Heart Disease (CHD), by creating a new channel through the coronary artery which is narrowed or blocked. The purpose of this research is to know the procedure of Cardiac CT examination with CABG case, acceptable Heart Rate range and how to lower Heart Rate range and how to lower Heart Rate at Radiologt Installation of MRCCC Siloam Hospital Semanggi.

Methods : This type of research is qualitative with case study approach. The data were collected from April - June 2017 at Radiology Installation of MRCCC Siloam Hospital Semanggi by observation method, interview with 3 radiographers, 2 radiology specialists and 1 sending doctor and documentation. Data obtained from the study were analyzed by interactive model, with data reduction stage, data presentation and conclusion.

Result : The results of this study stated that the procedure of Cardiac CT examination with CABG scan start from subclavia to the diaphragm to show the graft, the amount of contrast media used $20 \mathrm{cc}$ more and the amount of saline used $10 \mathrm{cc}$ more, Beta Blocker and Vasilidator not given because CT Scan with 256 slices work quickly so as to suppress the movement of the heart with optimal. Acceptable Heart Rate range is $65-80 \mathrm{bpm}$. How to lower high Heart Rate by giving patients education one day before the examination, which is does not consume drugs which can increase Heart Rate and do not perform heavy activities. Patients with unstable Heart Rate should be given Beta Blocker 2-3 days before the examination

Conlusion : Based on the results of the study, the range of CT Cardiac examination with CABG cases differs from the usual cardiac CT range and using MSCT 256 radiology specialists slice does not need to consider the patient's heart rate
\end{abstract}

Keywords : Heart Rate, Cardiac CT, Coronary Artery By Pass Grafting

\section{PENDAHULUAN}

Jantung adalah organ berongga dan memiliki empat ruang yang terletak antara kedua paru-paru di bagian tengah rongga thorax. Dua pertiga jantung terletak di sebelah kiri garis midsternal. Jantung dilindungi mediastinum. Jantung berukuran kurang lebih sebesar kepalan tangan pemiliknya, bentuknya seperti kerucut tumpul. Ujung atas yang lebar (dasar) mengarah ke bahu kanan serta ujung bawah yang mengerucut (apeks) mengarah ke panggul kiri (Sloane, 2004).

Penyakit aterosklerosis akan muncul pada saat arteri mengalami pengerasan dan penyempitan yang diakibatkan oleh adanya plak kolesterol yang menumpuk di dindingnya. Hal ini dapat menyebabkan Angina dan pecahnya sumbatan lemak di arteri yang terjadi akibat stenosis koroner. Stenosis koroner adalah penyempitan pada pembuluh darah arteri koroner. Jika sudah parah, maka prosedur Coronary Artery By Pass Grafting (CABG) adalah solusinya. Coronary Artery By Pass Grafting (CABG) adalah operasi untuk mengatasi stenosis pada sirkulasi arteri koroner dengan membuat jalur baru menggunakan arteri atau vena pasien itu sendiri (Rilanto.dkk, 1996).
Salah satu pemeriksaan penunjang untuk mengevaluasi Coronary Artery By Pass Grafting (CABG) adalah CT Cardiac adalah rangkaian pemeriksaan untuk menghasilkan pencitraan jantung dan bertujuan mengetahui endapan lemak atau endapan calsium pada pembuluh darah arteri koroner, sehingga dapat ditentukan treatment pengobatan yang lebih baik lagi bagi pasien (Garcia, 2005).

Untuk pemeriksaan CT Scan Cardiac, terdapat beberapa hal yang harus diperhatikan diantaranya adalah Heart Rate dan pemberian Beta Blocker. Heart Rate adalah jumlah detak jantung per satuan waktu yang biasa dinyatakan per menit / beats per menit (bpm) yang didasarkan pada jumlah kontraksi ventrikel. Heart Rate bisa diukur di belakang lutut, paha bagian dalam, leher, kaki, pelipis, pergelangan tangan dll. Biasanya paling mudah di pergelangan tangan dan leher. Nilai Heart Rate pasien yang dianjurkan untuk pemeriksaan CT Cardiac harus dibawah 70 bpm. Apabila nilai Heart Rate lebih dari 70 bpm, maka gambaran CT Cardiac yang dihasilkan kurang baik sehingga dianjurkan sebelum pemeriksaan pasien harus diberikan Beta Blocker (Galanski M.dkk, 2013).

Beta Blocker (kadang-kadang ditulis sebagai $\beta$-Pemblokir adalah obat-obatan yang digunakan untuk berbagai indikasi, 
tetapi terutama untuk pengelolaan aritmia jantung, cardio protection setelah infark miokard (serangan jantung), dan hipertensi. Sebagai beta adregenik reseptor antagonis, mereka mengurangi efek adrenalin dan hormon stress lainnya $(\mathrm{NN}$, 2013).

Selama penulis melakukan Praktek Kerja Lapangan (PKL) di Instalasi Radiologi Mochtar Riady Comprehensive Cancer Centre (MRCCC) Siloam Hospital Semanggi, pada tanggal 3 Januari - 27 Januari 2017 , penulis hanya menemukan 1 pasien yang melakukan pemeriksaan CT Cardiac dengan kasus CABG. Dari hasil wawancara penulis dengan radiografer, penulis mendapatkan informasi bahwa pemeriksaan CT Cardiac dengan kasus CABG sangat jarang ditemui. Dari awal MRCCC dibuka tahun 2011 hingga Januari 2017 pasien yang melakukan CT Cardiac dengan kasus Coronary Artery By Pass Grafting (CABG) sekitar <10 pasien. Pada Standart Operasional Prosedur (SOP) di Instalasi Radiologi MRCCC Siloam Hospital Semanggi batas range bagian atas untuk pemeriksaan CT Cardiac diatur setinggi Karina dan batas bawah diatur setinggi diafragma. Namun pada pasien CABG range diatur setinggi By Pass yang terpasang dijantung. Dan memiliki perbedaan dengan teori, pada teori sebelum pemeriksaan CT Cardiac pasien harus diberikan Beta Blocker. Hal inilah yang mendorong penulis untuk melakukan observasi pada pemeriksaan CT Cardiac dengan kasus CABG

\section{METODE}

Jenis penelitian ini adalah kualitatif dengan pendekatan studi kasus. Pengambilan data dilakukan pada bulan April Juni 2017 di Instalasi Radiologi MRCCC Siloam Hospital Semanggi dengan metode observasi, wawancara dengan 3 orang radiografer, 2 orang dokter spesialis radiologi dan 1 orang dokter pengirim serta dokumentasi. Data yang diperoleh dari penelitian dianalisis dengan interaktif model, dengan tahapan reduksi data, penyajian data dan penarikan kesimpulan.

\section{HASIL}

Pasien dengan nama Tn.MS/ MSHS000007*****, umur 56 Th, berasal dari Poli Medical Check Up, permintaan foto CT Cardiac dengan riwayat penyakit Stenosis koroner dan pernah melakukan operasi Coronary Artery By Pass Grafting (CABG) .

Sebelum dilakukan pemeriksaan CT Cardiac pasien diharuskan untuk puasa 4 jam sebelum pemeriksaan lalu pasien diwajibkan untuk melakukan pemeriksaan laboratorium berupa ureum, creatinin, dan eGfR. Persiapan alat dan bahan pada pemeriksaan MSCT 256 slice, Injector Double Syringe, Electro Cardiografi (ECG), Infus Set, Connector, Abocath ukuran 20, Three way, Alcohol swap, Plester dan dexametasone.

CT Cardiac pada pasien pasca operasi pintas jantung (CABG) memiliki perbedaan pada lokasi atau area scan dimana seluruh by pass graft harus tercover semua sehingga area scanning harus ditambah lebih ke arah superior sampai ke arteri subclavia kiri apabila untuk menilai Graft dari artery mamary interna kiri. Latihan instruksi aba-aba wajib dilakukan karena keberhasilan dari pemeriksaan CT Cardiac juga ditentukan oleh edukasi instruksi atau aba-aba dan teknik yang biasa digunakan untuk menentukan scan awal sebelum pemeriksaan dimulai adalah bolus tracking. Pasien tidak perlu diberikan Beta Blocker dan Vasilidator karena di MRCCC Siloam Hospital Semanggi telah menggunakan CT Scan 256slice.

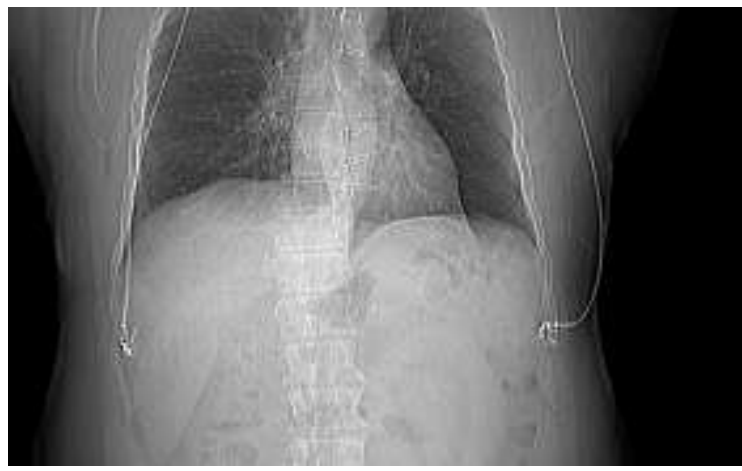

Gambar 1. Topogram CT Cardiac dibuat untuk ntuk topogram untuk mengetahui keadaan umum dari ketinggian klip by pass graft yang terpasang di jantung dan untuk menentukan daerah pengambilan scanning.

Berikut ini parameter pemeriksaan CT Cardiac dengan menggunakan MSCT Philip 256 Slice

Tabel 1. Parameter CT Cardiac pada alat Philip 256 slice

\begin{tabular}{ll}
\hline \multicolumn{1}{c}{ Parameter } & \multicolumn{1}{c}{ 256 Slice } \\
\hline $\begin{array}{l}\text { Tube voltage }(\mathrm{kV}) \\
\text { Tube current time product } \\
\text { (mAs) }\end{array}$ & 120 \\
Rotation Time & 000 \\
Detector Collimation $(\mathrm{mm})$ & $128 \times 0,625$ \\
Normal Pitch & 0,18 \\
Kernell & Xtress Standart \\
Slice Thickness & $0,6-1 \mathrm{~mm}$ \\
Scan Delay & 5,1 \\
Specials & ECG Pulsing < 80 \\
Scan Range & Subclavia kiri sampai dengan \\
Flow Rate & Base of Heart \\
& $4,5 \mathrm{cc}$ \\
Contras Media & $110 \mathrm{cc}$ \\
FOV & $80 \mathrm{cc}$ \\
Image Order & 250 \\
& $0 \%-90 \%$
\end{tabular}

Untuk membuat rekon CT Cardiac radiografer harus membuat irisan minimal $1 \mathrm{~mm}$ agarrekon yang di dapatkan maksimal. Pertama, pilh data image rekontruksi dengan \% fase yang clear tanpa blur, dengan cara melihat axial pembuluh darah pada Right Coronary Artery (RCA). Dengan memanfaatkan Software Cardiac CT Viewer dan fasilitas Compare. 


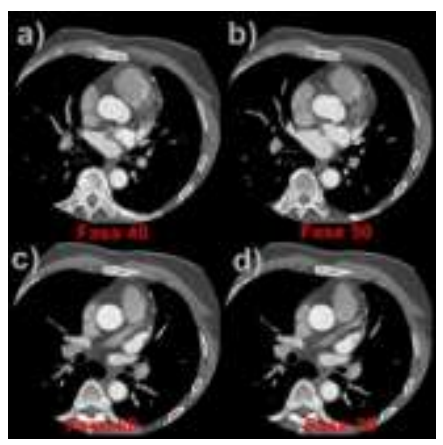

Gambar 2. Hasil pemeriksaan CT Cardiac a) Diambil pada saat Heart pasien 40 b) Diambil pada saat Heart Rate pasien 50\%, c) Diambil pada saat Heart Rate pasien 60\% d) Diambil pada saat Heart Rate pasien $70 \%$

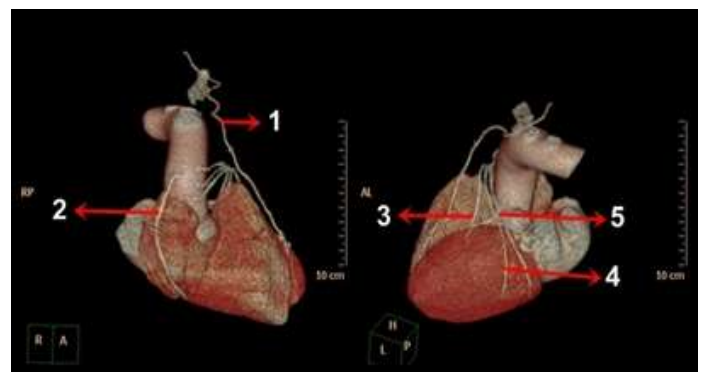

Gambar 3. Hasil Rekon MPR Cardiac a) CABG 1berasal dari artery subclavia proximal (LMA graft) b) CABG 2 berasal dari vena sapheneous dari anterior kanan aorta ascenden c) CABG 3 berasal dari dari pertengahan anterior ascendens aorta proksimal d) CABG 4 berasal dari dari pertengahan anterior ascendens aorta proksimal e)

CABG 5 berasal dari dari pertengahan anterior ascendens aorta proksimal

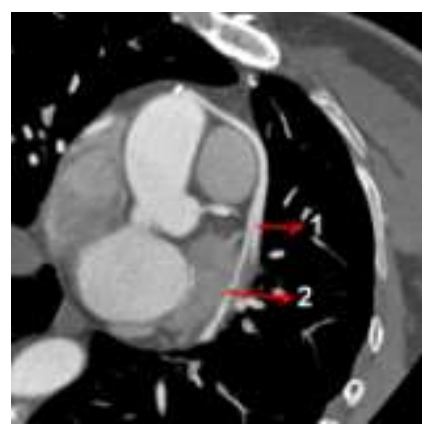

Gambar 4. Hasil VRT CT Cardiac 1) CABG 1 berasal dari artery subclavia proximal (LMA graft) yang dihubungkan ke bagian distal LAD 2) CABG 2 berasal dari vena sapheneous dari anterior kanan aorta ascenden dihubungkan ke distal RCA 3) CABG 3 berasal dari dari pertengahan anterior ascendens aorta proksimal dihubungkan ke proximal diagonal branch 4) CABG 4 berasal dari dari pertengahan anterior ascendens aorta proksimal dihubungkan ke marginal branch (OM) 5) CABG 5 berasal dari dari pertengahan anterior ascendens aorta proksimal dihubungkan ke distal dari LCx

\section{DISKUSI}

Pemeriksaan CT Cardiac dengan kasus CABG di Instalasi Radiologi MRCCC Siloam Hospital Semanggi memerlukan persiapan khusus. Sebelum dilakukan pemeriksaan CT Cardiac pasien harus di inform consent terlebih dahulu untuk meminta persetujuan pasien sebelum dilakukan dilakukan pemeriksaan CT Cardiac. Setelah itu pasien di anamnesa untuk mengetahui riwayat penyakit yang didertita oleh pasien dan untuk mengetahui obat-obatan yang sedang dikonsumsi oleh pasien. Harus dipastikan bahwa pasien tidak sedang mengkonsumsi obat diabetes dan obat pengencer darah.

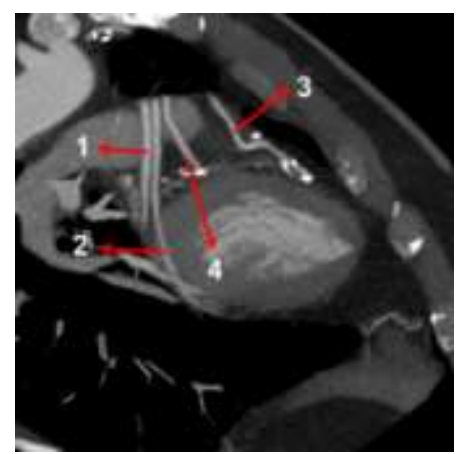

Gambar 5. Hasil Rekon MIP Cardiac dalam potongan Axial 1) CABG 3 2) $\mathrm{CABG} 4$

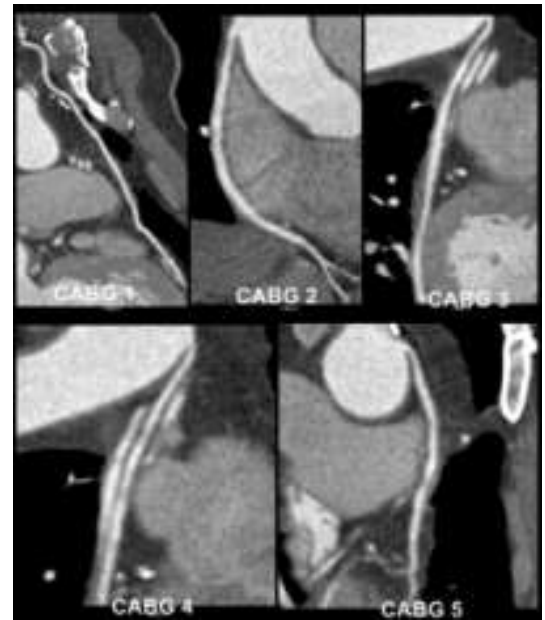

Gambar 6. Hasil Rekon MIP Jantung dalam potongan Sagital 1) CABG 2 ) CABG 4 3) CABG 3 4) CABG 5

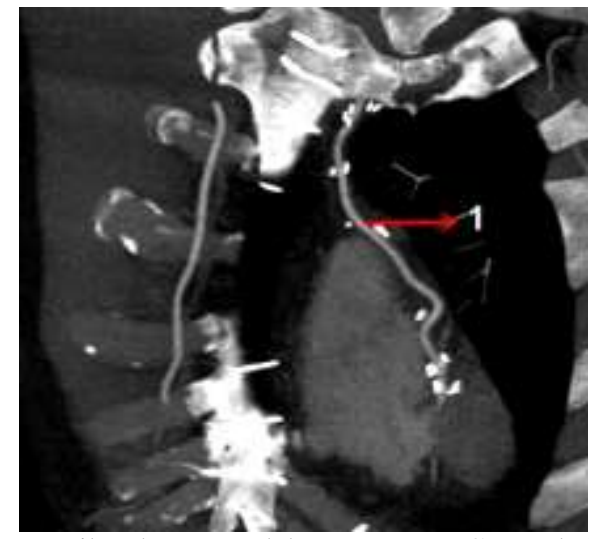

Gambar 7. Hasil Rekon MIP dalam potongan Coronal a) CABG 1

Karena apabila pasien sedang mengkonsumsi obat-obatan secara tidak langsung fisiologi jantung tidak berjalan normal sehingga pasien tidak dapat melakukan pemeriksaan CT Cardiac pada hari yang sama, disebabkan obat-obatan tersebut harus dihentikan minimal sehari sebelum pemeriksaan dan 
sehari setelah pemeriksaan. Sebelum pemeriksaan, pasien juga diharuskan untuk berpuasa minimal 4 jam dan pasien diharuskan melakukan pemeriksaan laboratorium yang terdiri dari : ureum, creatinin dan Glomelular Filtration Rate (GfR) untuk mengetahui fungsi ginjal. Sebaiknya hasil laboratorium yang digunakan adalah hasil laboratorium terbaru atau maksimal sebulan sebelum dilakukan pemeriksaan CT Cardiac.

Jumlah media Kontras yang digunakan pada pemeriksaan CT Cardiac lebih banyak 20 cc dari berat badan pasien. Karena pasien memiliki berat badan $60 \mathrm{~kg}$. Maka media kontras yang digunakan untuk pemeriksaan CT Cardiac dengan kasus CABG adalah $60+20=80 \mathrm{cc}$. Jumlah saline yang digunakan pada pemeriksaan CT Cardiac ditambah 10 cc dari jumlah saline awal yang biasa digunakan untuk CT Scan Kontras. Jumlah saline yang biasa digunakan pada pemeriksaan CT Scan dengan kontras adalah 100 cc. Maka saline yang digunakan untuk pemeriksaan CT Cardiac dengan kasus CABG adalah $100+10=110 \mathrm{cc}$. Jumlah yang digunakan sedikit lebih banyak dari jumlah media kontras yang digunakan pada pemeriksaan CT Cardiac karena pasien yang melakukan CABG memiliki pembuluh darah yang baru lebih panjang dari pembuluh darah yang lama. Dikhawatirkan apabila media kontras dan saline tidak dapat mengisi pembuluh darah yang baru dengan maksimal jika dengan dosis normal . Padahal pada pemeriksaan CT Cardiac dengan kasus CABG bertujuan untuk melihat keadaan pembuluh darah yang baru.

Beta Blocker adalah obat yang digunakan untuk menurunakan Heart Rate yang tinggi dan Vasilidator adalah obat yang diberikan untuk melebarkan pembuluh darah di jantung agar media kontras sampai ke distal pembuluh darah. Biasanya pada CT Scan 16, 32 dan 64 slice sebelum dilakukan pemeriksaan CT Cardiac pasien wajib diberikan Beta Blocker dan Vasilidator agar detak jantung pasien tidak terlalu tinggi sehingga gambaran jantung yang didapatkan maksimal. Namun berdasarkan pengamatan peneliti dan pernyataan responden 4 dan 5 (Dokter Spesialis Radiologi), Beta Blocker dan Vasilidator tidak diberikan kepada pasien sebelum pemeriksaan CT Cardiac dikarenakan di Instalasi Radiologi MRCCC Siloam Hospital Semanggi telah menggunakan CT Scan dengan jumlah slice yang tinggi yaitu 256 slice yang mampu mengambil gambaran jantung dengan cepat dengan hasil yang cukup baik.

Sebelum CT Cardiac dilakukan, radiografer harus membuat topogram untuk mengetahui keadaan umum dari ketinggian klip by pass graft yang terpasang di jantung dan untuk menentukan daerah pengambilan scanning. khusus, ketepatan waktu scan sangat menentukan kualitas imajing terutama arteri koroner. CT Cardiac pada pasien pasca operasi pintas jantung (CABG) memiliki perbedaan pada lokasi atau area scan dimana seluruh by pass graft harus tercover semua sehingga area scanning harus ditambah lebih ke arah superior sampai ke arteri subclavia kiri apabila untuk menilai Graft dari artery mamary interna kiri. Salah satu teknik yang biasa digunakan untuk menentukan scan awal sebelum pemeriksaan dimulai adalah bolus tracking yaitu dengan cara memonitoring kontras dengan melakukan scanning dinamik dan memasukkan treshoid tertentu atau kurang lebih $100 \mathrm{HU}$ dan apabila kurva penyangatan kontras sudah mencapai HU yang ditentukan maka scan akan berjalan secara otomatis.

Rentang Heart Rate yang diterima pada pemeriksaan CT Cardiac dengan kasus CABG 65- 80 bpm. Karena pada kasus CABG dokter pengirim hanya ingin melihat keberhasilan dari CABG, selain itu di Instalasi Radiologi telah menggunakan CT Scan dengan jumlah slice yang tinggi yaitu 256 slice yang mampu menekan pergerakan jantung sengan mengambil gambaran lebih cepat.

Cara mengatasi Heart Rate yang tinggi sebelum pemeriksaan CT Cardiac dilakukan dengan cara menginstruksikan kepada pasien bahwa sehari sebelum pemeriksaan pasien tidak boleh mengkonsumsi obat-obatan yang dapat meningkatkan Heart Rate, dan obat-obatan yang dapat merubah keadaan fungsional jantung. Karena pemeriksaan CT Cardiac ingin melihat kerja jantung secara normal tanpa bantuan obat-obatan. Pasien tidak diperbolehkan melakukan aktifitas berat seperti olahraga cardio karena apabila pasien beraktifitas berat secara langsung Heart Rate akan meningkat dan apabila Heart Rate meningkat maka pasien tidak dapat dilakukan pemeriksaan CT Cardiac.

Sebelum pemeriksaan dan pasien dengan Heart Rate yang tidak stabil harus diberikan Beta Blocker 2-3 hari sebelum pemeriksaan. Namun sebelum pemberian Beta Blocker dokter spesialis harus mengkonsultasikan kepada dokter pengirim demi keselamatan pasien agar tidak terlalu banyak mengkonsumsi obat-obatan. Selain itu pada saat pemeriksaan berlangsung radiografer juga harus tepat dalam menginstruksikan aba-aba tarik nafas pada pasien. Jika abaaba yang diberikan radiografer tidak tepat maka sangat berpengaruh dengan naik turunnya Heart Rate.

\section{KESIMPULAN}

Scan dimulai dari subclavicula sampai dengan diafragma untuk mengetahui graft yang terpasang, jumlah media kontras yang digunakan $80 \mathrm{cc}$ dan jumlah saline yang digunakan 110 cc, pasien tidak diberikan Beta Blocker dan Vasilidator Rentang Heart Rate yang diterima pada pemeriksaan CT Cardiac dengan kasus CABG di Instalasi Radiologi MRCCC Siloam Hospital Semanggi adalah $65-80 \mathrm{bpm}$. Hal ini dikarenakan alat CT Scan di Instalasi Radiologi MRCCC Siloam Hospital Semanggi memiliki jumlah slice yang tinggi yaitu 256 slice. Cara mengatasi Heart Rate yang tinggi sebelum pemeriksaan CT Cardiac dilakukan dengan cara menginstruksikan kepada pasien bahwa sehari sebelum pemeriksaan pasien tidak boleh mengkonsumsi obat-obatan yang dapat meningkatkan Heart Rate. Pasien tidak diperbolehkan melakukan aktifitas berat sebelum pemeriksaan dan pasien dengan Heart Rate yang tidak stabil harus diberikan Beta Blocker 2 - 3 hari sebelum pemeriksaan.

\section{DAFTAR PUSTAKA}

Bontrager, Kenneth L. 2010. Textbook of Positioning and Related Anatomy. Fifth Edition. CV. Mosby Company : St. Louis.

Bruering, R. 2006. Protocol Multi Slice CT. Second. Springer : New York. 
Braunwald, S. 2001. A Textbook of Cardiovascular Medicine, Single Volume: Expert Consult Premium Edition. Belanda.

Ignatavicus, MS. Finkelmaier D. 2006. Medical Surgical Nursing. Elseveier : Belanda.

Prokop, M. Galanski M. 2003. Cardiac Multi Slice CT. Spiral and Multislice Computer Tomografi of the body. Georg Thieme Verlag : Jerman.

Seeram, E. 2001 .Computed Tomography: physical principles, clinical applications, and quality control. Third edition. Philadelphia. WB Saunders Company

Sherwood, L. 2012. Fisiologi Manusia dari Sel ke Sistem. Edisi. EGC : Jakarta.

Sloane, E.2004. Anatomi dan Fisiologi Untuk Pemula. EGC : Jakarta.

Rilanto, K. 1996. Buku Ajar Kardiologi. Balai Penerbit FK UI : Jakarta.

Syaifuddin. 2009. Anatomi Tubuh Manusia Edisi 2. Salemba Medika : Jakarta. 